\title{
Juventudes e educação: 0 uso das tecnologias como ferramenta de aprendizagem em tempos de pandemia da covid-19
}

\author{
Maria das Graças Pereira Silva ${ }^{1}$ \\ Evelyn Monique dos Santos ${ }^{2}$ \\ Cláudia Lustosa Campos Dinizr ${ }^{3}$ \\ Geandro Richard da Silva Gomes Batista ${ }^{4}$
}

\begin{abstract}
Resumo:
O artigo insere-se na linha de pesquisa juventude e educação. Aborda, o tema Juventudes e Educação: o uso das tecnologias como ferramenta de aprendizagem em tempos de pandemia da covid19, o mesmo tem por objetivo: conhecer sobre juventudes, educação e o uso das tecnologias como ferramenta de aprendizagem em tempos de pandemia da covid-19. Objetivando especificamente 1) discutir acerca da juventude e educação e os efeitos nefastos da pandemia da covid-19; 2) discorrer sobre a pandemia da covid-19 fazendo uma reflexão sobre a educação pública; 3) descrever o uso das tecnologias como ferramenta de aprendizagem em tempos de covid-19. Em uma linha crítica de investigação e abordagem, para tanto, adota-se a abordagem qualitativa, em que a realização da pesquisa utiliza-se a análise bibliográfica. Tem como questionamento: em tempos de pandemia quais as contribuições dos programas e aplicativos utilizados no campo da educação como ferramenta de aprendizagem para jovens? Ressalta-se que a grande maioria dos jovens/estudantes não tem acesso a tecnologias, aplicativos e a internet para serem usadas como ferramenta de aprendizagem.
\end{abstract}

\section{Palavras-chave:}

Juventude. Educação. Uso de tecnologias. Ferramenta de aprendizagem. Covid-19.

\section{Youth and education: the use of technologies as a learning tool in times of the pandemic of the covid-19}

\footnotetext{
Abstract: The article is part of the line of research on youth and education. It addresses the theme Youths and Education: the use of technologies as a learning tool in times of pandemic of the covid-19, the same

1 Mestre em Educação, professora da rede municipal de ensino de Lajeado Tocantins. E-mail: gracaprofessor@gmail.com. ORCID iD: https://orcid.org/0000-0001-9318-9567.

2 Licenciada em Pedagogia, professora da Educação Básica da Secretaria de Estado da Educação, Juventude e Esportes do Tocantins. E-mail: evelynpedro84@gmail.com. ORCID iD: http://orcid.org/0000-0002-0258-9598.

3 Licenciada em Pedagogia. E-mail: claudiadiniz@uft.edu.br ORCID. iD: http://orcid.org/0000-0003-4132-1356.

4 Estudante de Pedagogia pela Universidade Federal do Tocantins, campus Miracema Tocantins. E-mail: geandro04@hotmail.com. ORCID iD: http://orcid.org/0000-0002-0258-9598.
} 
aims to: learn about youths, education and the use of technologies as a tool of learning in times of pandemic of covid-19. Specifically aiming at 1) discussing about youth and education and the harmful effects of the covid-19 pandemic; 2) talk about the covid-19 pandemic, reflecting on public education; 3) describe the use of technologies as a learning tool in times of covid-19. In a critical line of investigation and approach, for this purpose, the qualitative approach is adopted, in which the conduct of the research uses bibliographic analysis. The question is: in times of a pandemic, what are the contributions of programs and applications used in the field of education as a learning tool for young people? It should be noted that the vast majority of young people/students do not have access to technologies, applications and the internet to be used as a learning tool.

Keywords: Youth. Education. Use of technologies. Learning tool. Covid-19.

\section{Juventud y educación: el uso de las tecnologías como herramienta de aprendizaje en tiempos de la pandemia del covid-19}

Resumen: El artículo forma parte de la línea de investigación para la juventud y la educación. Aborda el tema Juventud y Educación: el uso de las tecnologías como herramienta de aprendizaje en tiempos de pandemia del covid-19, el mismo tiene como objetivo: conocer sobre los jóvenes, la educación y el uso de las tecnologías como herramienta de aprendizaje en tiempos de pandemia. de covid-19. Específicamente con el objetivo de 1) debatir sobre la juventud y la educación y los efectos nocivos de la pandemia del covid-19; 2) hablar sobre la pandemia del covid-19, reflexionando sobre la educación pública; 3) describir el uso de tecnologías como herramienta de aprendizaje en tiempos del covid-19. En una línea crítica de investigación y abordaje, para ello se adopta el abordaje cualitativo, en el que la conducción de la investigación utiliza el análisis bibliográfico. La pregunta es: en tiempos de pandemia, ¿cuáles son las contribuciones de los programas y aplicaciones que se utilizan en el campo de la educación como herramienta de aprendizaje para los jóvenes? Cabe señalar que la gran mayoría de jóvenes/estudiantes no tienen acceso a tecnologías, aplicaciones e internet para ser utilizadas como herramienta de aprendizaje.

Palabras clave: Juventud. Educación. Uso de tecnologías. Herramienta de aprendizaje. Covid-19.

\section{Introdução}

Os estudos sobre a juventude apontam, ao longo do tempo, diversas formas de considerá-la, pois, em cada sociedade, em diferentes contextos históricos e culturais, são definidos períodos etários no qual se determinam uma série de direitos e deveres para essa fase da vida (CONDÉ, 2016).

A relação entre juventude e educação, diante de inúmeras variáveis que a compõem como objeto de pesquisa, pode ser analisada sob diversas perspectivas. Neste trabalho, propõe-se a reflexão sobre a juventude, em se pensando as relações sociais construídas no espaço escolar, frente aos desafios impostos pela pandemia da covid-19, buscando discorrer acerca do uso das tecnologias como ferramenta do processo de ensino e aprendizado.

O ensejo pelo tema surge das inquietudes advindas do exercício da nossa profissão docente em tempos de pandemia, e por entendermos que especialmente na escola, a construção do conhecimento está, gradativamente, mediada por novas tecnologias e com perspectiva de formação de indivíduos para as exigências atuais do processo produtivo, cuja organização não prevê falhas de aprendizagens, por ser altamente competitiva e dinâmica.

Precisamos repensar o futuro da Educação, incluindo uma articulação apropriada entre o EAD e o Ensino presencial (UNESCO, 2020). Até porque, segundo Dias e Pinto (2020), nos apresenta que muitos no Brasil não têm acesso a computadores, celulares ou à internet de qualidade, 
realidade constatada pelas secretarias de Educação de Estados e municípios no atual momento, e um número considerável alto de professores precisou aprender a utilizar as plataformas digitais, inserir atividades online, avaliar os estudantes a distância e produzir e inserir nas plataformas material que ajude o aluno a entender os conteúdos, além das usuais aulas gravadas e online. $\mathrm{Na}$ pandemia, grande parte das escolas e das universidades estão fazendo o possível para garantir o uso das ferramentas digitais, mas sem terem o tempo hábil para testá-las ou capacitar o corpo docente e técnico-administrativo para utilizá-las corretamente.

O presente artigo se encontra estruturado em tópicos em que o marco teórico se encontra organizado em subtópicos, sendo o primeiro intitulado "A Juventude no Brasil: a geração ' $y$ "” descreve sobre a importância de estudos a respeito da juventude e dos fatores que impactam esses indivíduos, apresentando o conceito de juventude, além de discorrer sobre a geração " $y$ ".

O segundo subtópico que compõe o marco teórico tem como título "Juventude e educação vivendo os efeitos nefastos da pandemia da covid-19" e discorre acerca da juventude e educação e os efeitos da pandemia da covid -19 no sistema educacional. O terceiro subtópico tem como título "Tempos de pandemia da covid-19 uma reflexão necessária sobre a educação pública”, descreve os impactos causados pela pandemia; os reflexos da ausência do Estado no cumprimento do atendimento escolar e os cortes no apoio financeiro às ciências nos últimos. Quanto ao quarto subtópico, intitulado de "O uso das tecnologias como ferramenta de aprendizagem em tempos de covid-19", apresenta a forma como o processo educacional vem acontecendo, quais as plataformas são usadas e algumas reflexões acerca do processo de ensino e aprendizagem.

Além dos subtópicos acima mencionados, compõe a estrutura deste artigo, o resumo, acompanhado das palavras-chave; essa introdução; as considerações finais e a referências usadas na materialização deste artigo.

Para tanto, a realização da pesquisa utilizou-se a análise bibliográfica, em que a pesquisa de revisão bibliográfica foi realizada por meio do levantamento, seleção e estudo de diversas pesquisas que versam sobre juventude; educação; uso das tecnologias como ferramenta de aprendizagem e pandemia da covid-19.

Tem como objetivo geral: conhecer sobre juventudes, educação e o uso das tecnologias como ferramenta de aprendizagem em tempos de pandemia da covid-19. Objetivando especificamente: 1) discutir acerca da juventude e educação e os efeitos nefastos da pandemia da covid-19;2) discorrer sobre a pandemia da covid-19 fazendo uma reflexão sobre a educação pública; 3) descrever o uso das tecnologias como ferramenta de aprendizagem em tempos de covid-19.

Para escrita do artigo nos aportamos em teóricos como: Colomby, Salvagni e Cheron (2020); Condé (2016); Gabatz (2020); Dias e Pinto (2020); Santos (2020); Pasini, Carvalho e Almeida (2020); Rodrigues S. e Rodrigues Z. (2020); Pereira e Barros (2020), dentre outros autores. Além da Lei de Diretrizes e Base (LDB), Lei 9.394/96 (BRASIL, 1996), e também Organização das Nações Unidas para a Educação, a Ciência e a Cultura (UNESCO, 2020).

\section{Marco teórico}

\section{A juventude no Brasil: a geração " $y$ "}

Rodrigues (2017) relata que, apesar da importância de estudos a respeito da juventude e dos fatores que impactam esses indivíduos, a juventude é o assunto menos estudado no campo da demografia quando comparado a outros fenômenos, como migração, envelhecimento da população e aumento do número de divórcios e de arranjos unipessoais, afirma ainda que o mesmo acontece no que se refere a inserção dos Jovens no mercado de trabalho. 
Uma definição do que seria ou quem seriam hoje em dia os indivíduos alocados nesta camada da sociedade foi elaborada por Mello (2005, p. 25), em que o autor retrata que "juventude poderia ser definida como uma fase de transição entre os limites da dependência e da autonomia. Os jovens aparecem ora tendo pouca idade para algumas coisas, ora já tendo passado da idade para outras coisas".

Em consonância com Mello (2005), Dayrell (2003, p. 42) relata que, "juventude constitui um momento determinado, mas não se reduz a uma passagem, pois os jovens se apresentam como sujeitos sociais, que vivem e se constitui como tais nas relações estabelecidas no seu cotidiano".

Podemos constatar, mediante ideias de Rodrigues (2017), que a juventude não foi sempre assim, o autor relata que no início do século XX, a juventude nem sequer possuía uma existência social, pois os indivíduos passavam diretamente da condição de criança para condição de adulto.

No Brasil, tratando-se da parte oficial do conceito de juventude, temos a descrição estabelecida pela Secretaria Nacional de Juventude que define como jovens aqueles que possui entre 15 e 29 anos, de acordo com artigo 11 da Lei no 11.129/2005, que institui o Programa Nacional de Inclusão de Jovens - ProJovem; cria o Conselho Nacional da Juventude - CNJ e a Secretaria Nacional de Juventude; altera as Leis no 10.683, de 28 de maio de 2003, e 10.429, de 24 de abril de 2002; e dá outras providências (BRASIL, 2005).

Rodrigues (2017) escreve que jovens também são retratados como indivíduos que se encontram em um período inicial de seu desenvolvimento orgânico. O termo provém do latim "juventus" para referir à idade situada entre a infância e a idade adulta.

Para a Organização das Nações Unidas, a extensão da juventude pode variar desde os 10 aos 23 anos, tanto na puberdade como na adolescência tardia, até chegar à juventude propriamente dita. No Brasil, de acordo com a PEC da Juventude aprovada pelo congresso em setembro de 2010 e o Estatuto da Juventude sancionado em 2013, considera-se jovem no Brasil todo cidadão que compreende a idade entre 15 e 29 anos de idade.

Rodrigues (2017), destaca que o conceito de juventude na atualidade ainda é muito relacionado com a temática da geração $y$. Para tanto, para que se entenda como é a juventude brasileira, é importante evidenciar as principais características dessa geração. Diretamente impactados pela evolução tecnológica e pela globalização, os indivíduos pertencentes à geração $y$ possuem características peculiares. Apesar de não haver muitos estudos sobre a temática de geração $y$, pois não existe uma definição padrão, ou oficial, a respeito desta geração. Porém, podemos observar diversos pontos em comum nas mais variadas definições da geração $y$.

De acordo com Rodrigues (2017),

[...] a geração $y$ representa a geração descendente da Geração Baby Boomers, que por sua vez é representada pelos indivíduos nascidos entre os anos de 1964 e 1977 portanto, a geração y corresponde aos indivíduos nascido entre 1978 e 1994. É a geração dos resultados, nasceram na era das inovações tecnológicas, da internet, do excesso de segurança e do recebimento de estímulos constantes por parte dos pais. (RODRIGUES, 2017, p. 49).

Já Oliveira (2009) afirma que a geração y é motivada por desafios e interesse de ascensão rápida, buscando rotatividade nas suas atividades, essa nova geração possui importantes particularidades, pois nasceu na era da tecnologia, da internet e do acesso de informação, não passou por nenhuma importante ruptura no parâmetro social, habituado com a democracia, a liberdade política e prosperidade econômica.

Para Maciel (2010), a geração $y$ também busca:

Ter experiências profissionais significativas, o que se relaciona principalmente com a reputação da organização em que trabalha e às oportunidades de crescimento pessoal mediante a exportação para outros países, contato com funcionários de outras culturas ou viagens. Os 
indivíduos dessa geração são mais críticos em relação à reputação das companhias, valorizando aquelas que têm iniciativas de responsabilidade social e ambiental, e buscam aquelas que possuem uma filosofia compatível com os seus valores pessoais. (MACIEL, 2010, p. 33).

O agrupamento de todo o grupo em um conceito amplo como geração $y$ pode distorcer os estudos, principalmente quando relacionado a inserção de jovens no mercado de trabalho. Se assumirmos a geração $y$ como a classe jovem atual, temos de aceitar que todos os jovens estão imersos na tecnologia e na globalização, porém é sabido que há muitas das redes públicas de educação no Brasil não oferece sequer um computador para os estudantes (RODRIGUES, 2017).

Parafraseando Rodrigues (2017), diante de todas essas alterações no mundo e no mercado do trabalho, estão os jovens, em busca de educação de qualidade para enfim conseguir o tão sonhado primeiro emprego. Estes jovens hoje são os indivíduos que moldam o mundo do trabalho, entretanto, atualmente poucos conseguem emprego nas carreiras almejadas. Mesmo quando possui qualificação, migram de um emprego para outro veículo até chegar ao objetivo estabelecido, sendo que nem sempre isso acontece. Quando não possui qualificação, são obrigados a aceitar trabalhos voluntários ou estágios para se almejar uma possível efetivação e com ela ainda uma baixa renumeração.

Juventude e educação vivendo os efeitos nefastos da pandemia da covid-19

\begin{abstract}
Um mundo que maximize a necessidade e não o desejo das pessoas é um mundo menos frágil, mais resiliente e, aprendemos, mais feliz. Se a lição histórica que o vírus que trancou mais da metade do mundo em casa, matou centenas de milhares de pessoas e destruiu, mesmo que temporariamente, a economia mundial servirá para desenharmos um futuro diferente ainda é cedo para dizer. Porque para isso precisaremos enfrentar um inimigo ainda mais forte do que o vírus. Nossos desejos. (MOREIRA, 2020, p. 64).
\end{abstract}

A população mundial tem vivenciado a pandemia mundial de covid-19, que, para Colomby, Salvagni e Cheron (2020, p. 8), é uma dessas “coisas” que, para tentarmos conhecer, nos exige "dar-lhes a volta", mais de uma vez, com diferentes olhares.

Assim, citamos Mbembe (2018), que ainda no ano de 2018 destaca que a situação atual evidencia uma espécie de necropolítica “à brasileira”, que se amplia pela negação das desigualdades sociais já existentes. Ocorre uma negligência da governança pública em relação aos conflitos e às diferenças, no campo educacional também é possível perceber esses conflitos, sobretudo ao que se refere ao processo de formação de professores e sua qualificação para o processo de ensino e aprendizado dos jovens.

Tendo como embasamento os estudos em Condé (2016), percebe-se que as transformações sociais, políticas, econômicas, culturais e tecnológicas impõem, hoje, uma (re)significação dinâmica e constante das relações entre os indivíduos em todas as esferas: na família, no trabalho, no momento/local de lazer, na comunidade, nas redes sociais virtuais, e também, na escola.

A autora supramencionada nos leva a reflexão de que a organização social permeada por tecnologias cada vez mais inovadoras, a compressão do espaço-tempo, a velocidade das informações, a escassez dos recursos naturais, as relações sociais cada vez mais individualistas, baseadas, principalmente, pela evocação da igualdade, da escolha e do consumo, e todas as desigualdades oriundas delas são, proporcionalmente, vividas no âmbito da escola.

De acordo com Gabatz (2020), os cortes no apoio financeiro às ciências nos últimos anos mostram os efeitos nefastos da estratégia que tem sido adotada. De positivo, este momento parece estar evidenciando a valorização do Sistema Único de Saúde (SUS) e um reforço à manutenção de um sistema público de saúde. O Sistema público de Educação tem sofrido com a falta de recursos, 
atenção e de orientação por parte do Ministério de Educação; Secretarias Estaduais e Municipais de Educação. Gestores escolares juntamente com equipe técnica e administrativa, professores, estudantes, pais e comunidades locais, têm vivido tempos de angústias, e ao mesmo tempo criado métodos de trabalhar no intuito de não deixar os estudantes e familiares em estado de abandono.

A estrutura social excludente e suas contradições estão a todo momento permeando o processo pedagógico de ensinar e aprender da juventude brasileira, e todas as etapas que dele fazem parte, antes ou após o espaço de aprendizagem, pois a educação escolar tem enfrentando desde de março de 2020, quanto teve suas atividades presenciais interrompidas em virtude da pandemia da covid-19 desafios significativos em sua organização cotidiana.

Desse modo, o que temos presenciado é o que aqui expõe Santos (2020):

Na presente crise humanitária, os governos [...] falharam [...] na luta contra a pandemia. Ocultaram informação, desprestigiaram a comunidade científica, minimizaram os efeitos potenciais da pandemia,utilizaram a crise humanitária para chicana política. Sob opretexto de salvar a economia, correram riscos irresponsáveis pelos quais, esperamos, serão responsabilizados. Deram a entender que uma dose de darwinismo social seria benéfica: a eliminação de parte das populações que já não interessam à economia, nem como trabalhadores nem como consumidores, ou seja, populações descartáveis como se a economia pudesse prosperar sobre uma pilha de cadáveres ou de corpos desprovidos de qualquer rendimento. (SANTOS, 2020, p. 26).

Diante de tal situação no campo da educação, equipe diretiva e professores buscam fortalecer junto aos estudantes os aspectos culturais, sociais, políticos e econômicos intensificando as relações sociais e estruturas pertencentes à sociedade onde vivem. Porém é perceptível que a crise humanitária citada por Santos (2020), afeta a vida escolar de diversas formas, o que ocasiona a não ampliação do papel da escola na formação de indivíduos capazes de responder às demandas de mercado específicas e, ao mesmo tempo, de serem cidadãos críticos.

Gabatz (2020, p. 31) relata que é:

[...] temeroso afirmar que a covid-19, de alguma forma, tenha igualado os seres humanos. Mais correto talvez fosse acentuar que ela dimensionou melhor algumas percepções que os indivíduos têm, por exemplo, em relação à situação do sistema de saúde no Brasil. Parece ter havido uma maior clareza sobre determinados marcadores sociais que possibilitam o acesso a tratamento de saúde para viver ou sobreviver. A pandemia, nessa direção, inexoravelmente, alimentou também alguns falsos profetas e veio a contaminar os meandros da ação política, provocando o devaneio e o mal estar da confirmação de um de nossos maiores paradoxos: a dolorosa desigualdade social. (GABATZ, 2020, p. 31).

Diante da dolorosa desigualdade social, citada por Gabatz (2020), no meio educacional, ainda que a intensa difusão do uso de recursos e ferramentas multimídias como o computador, o tablet, o smartphone e as NTICs (novas tecnologias de informação e comunicação) associadas ao processo ensino aprendizagem acentuam a configuração de uma sociedade contemporânea pautada pela informação, pela técnica e pelo conhecimento, estas ferramentas não chegam às mãos de todos os jovens estudantes.

Que percebemos com bastante clareza, a partir dessa discussão no que se refere ao uso de tecnologias no período da pandemia, é o fato de que esta pandemia tem evidenciado a desigualdade que marca nossa sociedade, pois, enquanto alguns estudantes têm acesso à tecnologias de ponta, possuem acesso ilimitado à internet e recebem em casa o apoio dos pais/responsáveis, tantas outras ficam à margem deste processo, seja pela falta de equipamento tecnológico adequado em casa, seja pelo fato de os responsáveis dedicarem-se à outras preocupações, seja por estes não terem a formação escolar adequada para orientá-los em relação à realização das atividades ou, ainda, por situações de extrema pobreza e vulnerabilidade social. 
Por outro lado, Condé (2016), afiança que, a escola agrega o papel de formadora de cidadãos e sistematizadora de saberes formais para uma demanda crescente de exigências do mercado de trabalho global. Especialmente na etapa do ensino médio, ainda são somadas a essas características as condições sociais próprias dos jovens estudantes, tais como as relações sociais vividas, a condição familiar, as perspectivas de futuro e o contexto socioeconômico.

Tendo como ponto de partida as reflexões de Condé (2016), é imprescindível, portanto, que as escolas refaçam seus planejamentos, pensando em como recuperar as aprendizagens que tiveram prejuízo pedagógico. Além disso, é imprescindível também que seja atribuído maior enfoque ao acolhimento destes estudantes e jovens, destinando-os a um olhar atento, que nos possibilita estar sensíveis à identificação não só dos prejuízos escolares, mas de possíveis situações de violências, bem como questões de prejuízo da saúde mental. Em resumo, a desigualdade e vulnerabilidade, já visível, e muitas vezes ignorada, na escola presencial, foi fortemente acentuada com a pandemia.

No momento em que escrevemos esse artigo, pensamos que nos resta a despeito de tantos infortúnios vivenciadas em decorrência da pandemia da covid-19, que tenhamos a capacidade de seguir adiante valendo-nos de uma experiência de vida capaz de tomar outros contornos por meio da esperança de dias melhores. Que cada qual tenha a capacidade de cultivar essa esperança, sem a qual os olhos, a boca e os corpos definham.

\section{Tempos de pandemia da covid-19: uma reflexão necessária sobre a educação pública}

Se sobrevivermos, vamos brigar pelos pedaços de planeta que a gente não comeu, e os nossos netos ou tataranetos - ou os netos de nossos tataranetos - vão poder passear para ver como era a Terra no passado (KRENAK, 2019, p. 8).

Este estudo acerca da covid-19, assim como as demais abordagens presentes neste artigo, foi realizado no período de confinamento, quando medo, ansiedade e notícias estarrecedoras da Itália, da Espanha, dos Estados Unidos e do Brasil tornaram o mundo um lugar mais complexo. A pandemia talvez tenha a capacidade de dizer mais sobre nós mesmos do que a doença em si. Em meio a múltiplas incertezas, a sociedade brasileira parece estar convivendo, como em nenhuma outra época da sua trajetória, com o negacionismo e uma profunda crise política, a qual se amplia também por conta de uma assustadora falta de empatia, insensibilidade e desrespeito às milhares de vidas perdidas.

No campo da educação, por exemplo, conforme a Organização das Nações Unidas para a Educação, a Ciência e a Cultura (UNESCO), a crise causada pela covid-19 resultou no encerramento das aulas em escolas e em universidades, afetando mais de $90 \%$ dos estudantes do mundo (UNESCO, 2020). A partir desse número, pergunta-se: qual o futuro da Educação num mundo abalado pelo novo coronavírus?

Desse modo, diante da pandemia que atravessamos neste momento, um debate se faz necessário para professores, estudantes e toda a comunidade escolar. É correto abrir mão da qualidade do ensino? O governo pode-se utilizar de uma situação de calamidade pública para impor um EAD e reestruturar a educação?

Do ponto de vista de Dias e Pinto (2020), quando as escolas reabrirem, e, em algumas partes do mundo, tal evento já começou a ocorrer, a emergente recessão econômica, certamente, aumentará as desigualdades e poderá reverter o progresso obtido por alguns países na expansão do acesso educacional e na melhoria da aprendizagem. Por isso, é necessário que os países reconheçam o problema, como não o fizeram quando a covid-19 começou a espalhar-se pelo mundo, e criem políticas públicas voltadas especificamente para a Educação.

Essa preocupação apresentada por Dias e Pinto (2020) só confirma o que já afirmava Condé (2016), quando descreve que todas essas transformações sociais vivenciadas na contemporaneidade são sentidas na escola, que, por sua vez, recebe a atribuição de papéis que viabilizam a socialização 
e a construção de indivíduos específicos para a organização da vida social. Ou seja, a escola é impactada pelas mudanças sociais e opera na assimilação dessas novas condições de vida e no direcionamento da formação de novos sujeitos para a realidade.

Para Gabatz (2020), nesses tempos de pandemia,

[...] há, por óbvio, muitos questionamentos sobre o fato de uma grande parcela da população brasileira ignorar as orientações dos órgãos oficiais de saúde sobre a indicação do isolamento como forma de conter a propagação do vírus. Para entender os motivos, é preciso reconhecer que, além de certos protagonistas da governança pública, existe a negação histórica do acesso a uma educação capaz de transformar corações e mentes e que, em momentos iguais ao que estamos vivendo, agrava-se o caos do social. Essa negação, cunhada na estrutura de uma sociedade racista, patriarcal e de exploração, perdura por meio de nossa herança escravagista colonial, potencializada na recrudescência dessa incapacidade de aceitar opiniões divergentes, transformando o outro em inimigo e, portanto, sempre induzindo ao pensamento de que se deveria viver em outros países, pois, talvez, aqui não haja dignidade para o exercício da cidadania. (GABATZ, 2020, p. 22, grifo nosso).

O que temos presenciado desde março de 2020 são estabelecimentos de Ensino como: creches, escolas, universidades, com suas atividades escolares presenciais suspensas, o que atinge milhões de estudantes em todo o país. Apesar do fato ser terrível e estar prejudicando o ensino e a aprendizagem, a suspensão das aulas é medida essencial para se evitar a propagação da contaminação, tendo em vista que a escola é um ambiente de natural contato.

Todavia, há a percepção coletiva das autoridades, gestores e professores de que a educação não pode parar, com o objetivo de não perdermos o ano letivo. Surge, então, a necessidade da adaptação e da superação por parte de professores e alunos.

Pasini, Carvalho e Almeida (2020) destacam que os tempos de pandemia pelo Coronavírus (covid-19) trouxe uma ressignificação para a educação, nunca antes imaginada. A dor causada pela perda de pessoas, o afastamento, o isolamento social, causaram uma desestruturação no sistema regular e presencial de ensino. A crise sanitária está trazendo uma revolução pedagógica para o ensino presencial, a mais forte desde o surgimento da tecnologia contemporânea de informação e de comunicação.

Para Gabatz (2020), na maioria das vezes, quanto maior a renda, maior a chance de realizar algum trabalho remoto. Na escolha, entra a vida ou a economia, uma parcela da sociedade, sobretudo das classes abastadas e mais pobres, compra o discurso de que é melhor continuar trabalhando ao invés de morrer de fome.

Um país como o Brasil, nascido e estruturado com base em tantas situações injustas, tem produzido práticas e relações muito desiguais. Nelas, os sujeitos que sofrem a ação de precarização de suas vidas seguem os critérios de classe, raça e gênero. Precarizar vidas é torná-las também 'descartáveis'. Quem mais sofre os impactos do vírus são as populações diariamente submetidas a condições de vida na qual eles, de certa maneira, já são mortos-vivos. A insistência no argumento de que é preciso privilegiar o funcionamento da economia em detrimento das medidas de isolamento social soa como um evidente paradoxo. Afinal, diz-se que nossas indústrias estão com dificuldades, mas, por outro lado, finge-se não reconhecer as pessoas que estão morrendo por falta de leitos em hospitais. (GABATZ, 2020, p. 23).

Diante das circunstâncias apresentadas por Gabatz (2020), o campo educacional deveria pautar-se sempre na busca pela transformação e preparação para o futuro, considerando os processos sociais e culturais articulados a esse fenômeno. O que é possível identificar, no entanto, são sinais históricos desordenados entre o que a escola regular oferece e o que a sociedade efetivamente necessita. 
Se pensarmos que a Educação como um direito social foi instituída na década de 1930, mas que tenha sido somente em 1988 que o ensino obrigatório foi assumido pela Constituição, visualiza-se o tamanho da reparação histórica que este país ainda necessita realizar para com a sua população. Na medida em que a reparação histórica não se realiza, estaremos submetidos à perversidade de quem não tem nenhum pudor em garantir os seus interesses.

Conforme a Unesco, a natural queda na aprendizagem poderá alastrar-se por mais de uma década se não forem criadas políticas públicas que invistam em melhorias de infraestrutura, tecnologias, formação, metodologias e salários, além do reforço da merenda, melhor aproveitamento do tempo, tutoria fora do horário usual das aulas e material adicional, quando possível (UNESCO, 2020).

Para tanto, faz-se necessário que tenhamos claro que para construirmos um futuro mais saudável, próspero e seguro, precisamos de políticas públicas que garantam um financiamento adequado para a Educação, fazer uso inteligente das tecnologias disponíveis, priorizar os mais vulneráveis e proteger educadores e alunos. O Estado precisa se fazer presente.

\section{O uso das tecnologias como ferramenta de aprendizagem em tempos de covid-19}

Sim, é preciso fazer. É urgente decidir. É necessário optar. Porém, questiona-se: com quais recursos? Com quais estruturas institucionais e humanas? Com quais fundamentos pedagógicos e metodológicos? Com quais tecnologias? Como envolver as pessoas e responsabilizar governantes e gestores, componentes das ambiências institucionais decisórias? E, antes de tudo, com quais recursos financeiros? (RODRIGUES S.; RODRIGUES Z., 2020, p. 54).

Bem antes da existência da pandemia da covid-19, Condé (2016), relatava acerca da relevância do uso das tecnologias no meio educacional quando afirmava:

[...] que as transformações sociais mais contundentes das últimas décadas nos direcionam para mudanças sensíveis na organização escolar. As dinâmicas estruturais de ordem econômica, política, social, cultural nas sociedades repercutem nas mudanças profundas das relações sociais, nas interações e comunicação entre os indivíduos, na organização do espaço/tempo, nas formas de produção e, como não poderia deixar de ser, na disseminação - quase coercitiva - da tecnologia e da informação em todas as esferas da vida social. (CONDÉ, 2016, p. 37).

Pasini, Carvalho e Almeida (2020) destacam que, apesar de a Educação a Distância (EAD) já ser uma realidade na educação brasileira, ele estava direcionado quase que na sua totalidade para o Ensino Superior, sendo outra parte para os cursos técnicos profissionalizantes. Na Educação Básica (Educação Infantil, Ensino Fundamental e Médio), a regra geral das escolas, quando utilizadas, tendia para o EAD apenas como forma de educação complementar, sendo autorizado o EAD para casos específicos do Ensino Médio, especialmente para cursos profissionalizantes.

Essa organização que era realizada dentro dessa logística, apresentada pelos autores Pasini, Carvalho e Almeida (2020), se dá em atendimento ao parágrafo 4o do art. 32 da Lei no 9.394, de 20 de dezembro de 1996 (Lei de Diretrizes e Bases da Educação - LDB), que define que "O ensino fundamental será presencial, sendo o ensino a distância utilizado como complementação da aprendizagem ou em situações emergenciais" (BRASIL, 1996, p. 11).

A covid-19 nos levou a uma dessas situações emergenciais. A pandemia afastou os alunos presenciais, da educação básica e do ensino superior, das salas de aula. Os gestores educacionais ficaram naturalmente atônitos e a reação demorou um pouco a ocorrer. Surgiram, então, as necessidades de adaptação e de superação, tanto por parte da gestão, dos professores quanto pelos estudantes, incluindo toda a sociedade (PASINI; CARVALHO; ALMEIDA, 2020). 
Entendemos que a educação está sendo modificada pela adaptação de gestores, professores, estudantes, pais e demais envolvidos no processo educacional, essa modificação tem acontecido por meio de diversos programas, aplicativos, ferramentas que passaram a ser utilizadas na educação. A seguir, apresentamos no quadro 1 alguns desses instrumentos para a educação emergencial, sabemos que existem muitos outros, mas todos aqui apresentados foram testados pelos autores deste artigo.

Quadro 1: Programas e aplicativos utilizados para as aulas em tempo de pandemia

\begin{tabular}{|c|c|c|}
\hline Nome & Principal utilização & Algumas funcionalidades \\
\hline Sistema Moodle & $\begin{array}{l}\text { Organização da discipli- } \\
\text { na e de Cursos e aulas } \\
\text { On-Line }\end{array}$ & $\begin{array}{l}\text { O programa permite a criação de cursos on-line, páginas de disciplinas, grupos } \\
\text { de trabalho e comunidades de aprendizagem, estando disponível em } 75 \text { idio- } \\
\text { mas diferentes. A plataforma é gratuita e riquíssima, aceitando vídeos, arquivos } \\
\text { diversos. Já está sendo amplamente utilizada na UFSM. }\end{array}$ \\
\hline $\begin{array}{l}\text { Google } \\
\text { Classroom }\end{array}$ & $\begin{array}{l}\text { Organização da discipli- } \\
\text { na e de Cursos e aulas } \\
\text { On-Line }\end{array}$ & $\begin{array}{c}\text { O Google Sala de aula (Google Classroom) é um serviço grátis para professores } \\
\text { e alunos. A turma, depois de conectada, passa a organizar as tarefas online. O } \\
\text { programa permite a criação de cursos on-line, páginas de disciplinas, grupos de } \\
\text { trabalho e comunidades de aprendizagem. }\end{array}$ \\
\hline YouTube & $\begin{array}{l}\text { Transmissão de aulas e } \\
\text { repositório de vídeos }\end{array}$ & $\begin{array}{l}\text { Plataforma de compartilhamento de vídeos e de transmissão de conteúdo (ao } \\
\text { vivo - Lives ou gravados). O professor pode criar o "seu canal" e ser acompa- } \\
\text { nhado pelos estudantes, já acostumados com a plataforma. }\end{array}$ \\
\hline Facebook & $\begin{array}{l}\text { Transmissão de aulas e } \\
\text { informações em grupos } \\
\text { fechados }\end{array}$ & $\begin{array}{l}\text { Mais destinado ao Ensino Médio e à Educação Superior, o professor pode criar } \\
\text { um "Grupo Fechado", onde ele realiza perguntas iniciais de identificação dos } \\
\text { usuários. Nessa plataforma, o docente pode incluir conteúdos e realizar lives } \\
\text { (aulas on-line), que já ficam automaticamente gravadas. }\end{array}$ \\
\hline StreamYard & $\begin{array}{l}\text { Transmissão on-line e } \\
\text { videoconferência }\end{array}$ & $\begin{array}{l}\text { Estúdio on-line gratuito para lives com um ou mais profissionais. Ele pode ser } \\
\text { relacionado ao YouTube ou ao Facebook. Possui uma versão paga, com maiores } \\
\text { aplicações, mas a gratuita auxilia nas atividades docentes. }\end{array}$ \\
\hline OBS Estúdio & $\begin{array}{l}\text { Transmissão on-line e } \\
\text { videoconferência }\end{array}$ & $\begin{array}{l}\text { O Open Broadcaster Software, que pode ser traduzido como Software de Trans- } \\
\text { missão Aberta, realiza a mesma atividade que o Stream Yard, mas pode realizar } \\
\text { gravação ou transmissão on-line. Ou seja, diferentemente do StreamYard, o } \\
\text { professor baixará um aplicativo no seu computador, onde poderá realizar as } \\
\text { atividades de transmissão ou gravação. }\end{array}$ \\
\hline Google Drive & $\begin{array}{l}\text { Armazenamento de } \\
\text { arquivos nas nuvens }\end{array}$ & $\begin{array}{c}\text { Além de economizar o espaço do equipamento tecnológico, o Google Drive per- } \\
\text { mite o compartilhamento de arquivos pela internet para os alunos. Por exemplo, } \\
\text { após carregar o arquivo para a "nuvem" da internet, o professor pode criar um } \\
\text { link compartilhável. Até } 15 \text { Gb de memória o Google Drive é gratuito. Excelente } \\
\text { ferramenta de criação de arquivos de recuperação. }\end{array}$ \\
\hline Google Meet & Videoconferências & $\begin{array}{c}\text { Aplicativo para fazer videoconferências online, com diversos participantes, até } \\
100 \text { na versão gratuita, tendo o tempo máximo de } 60 \text { minutos por reunião, } \\
\text { nesta versão. Existe uma versão paga, quando o tempo é livre e a quantidade } \\
\text { de participantes aumenta para } 250 .\end{array}$ \\
\hline Jitsi Meet & Videoconferências & $\begin{array}{l}\text { Aplicativo para fazer videoconferências online, gratuito, que funciona dentro do } \\
\text { Moodle. Possui as mesmas funcionalidades do Google Meet. }\end{array}$ \\
\hline
\end{tabular}

Fonte: Elaborado pelos autores (2021), adaptado de Pasini, Carvalho e Almeida (2020). 
Por outro lado, entendemos que esta mudança súbita nos processos educacionais tem gerado muitas incertezas por parte dos gestores das escolas, professores, estudantes, pais e comunidade científica acerca da eficácia do ensino não presencial, mediado pelas tecnologias digitais, quanto à aprendizagem, principalmente na educação básica e secundária, quando comparado ao ensino presencial a que todos estavam acostumados.

Pereira e Barros (2020) afirmam ser necessário considerar a inserção de todos num contexto mundial e por esse fato não se pode ficar à margem dos acontecimentos e das consequências, nem sempre positivas.

A educação deveria ser beneficiada e privilegiada com os avanços tecnológicos, porém, infelizmente não é devidamente contemplada como deveria, afinal, mesmo considerada prioridade pelos órgãos governamentais, continua de modo geral, obsoleta em tecnologia e elitista, na qual os menos favorecidos lutam por uma escola pública de maior qualidade e por um acesso à universidade mais democrático e menos excludente. Por estarem inseridos nesse contexto, os alunos observam uma situação crítica, o que lhes provoca desestímulo e falta de perspectiva em relação às suas vidas e ao futuro. Isso tudo, acaba por desencadear elevados índices de repetência e evasão escolar, ou seja, o insucesso do processo ensino-aprendizagem. Somam-se a isso outros problemas de ordem pessoal, social e familiar que comprometem o processo ensino-aprendizagem, uma vez que afloram na escola e no meio próximo a esta. (PEREIRA; BARROS, 2020, p. 4, grifo nosso).

Temos conhecimento que as diversas desigualdades socioeconômicas que caracterizam o Brasil determinam fortemente as condições de acesso aos benefícios das modernas tecnologias da informação.

Nesse sentido, conforme Vieira e Silva (2020), a compreensão do impacto da covid-19 sobre a Educação é de suma importância, no sentido de se buscar maneiras de aperfeiçoar as medidas ora tomadas para o futuro próximo.

O maior desafio da educação brasileira passou a ser a adequação ao novo cenário imposto pela pandemia, em razão das medidas emergenciais adotadas pelos governantes e dirigentes escolares, nomeadamente, a adoção do ensino remoto nas escolas com utilização de plataformas digitais e sistemas gerenciadores de cursos remotos como alternativa à suspensão das atividades presenciais. Aliado a este, outro grande desafio é o desenvolvimento de habilidades e competências digitais docente, de maneira ainda mais urgente pois, a implantação do ensino remoto vem evidenciando ainda mais as disparidades socioeconômicas e culturais existentes no Brasil (VIEIRA; SILVA, 2020).

Como sinaliza Nóvoa (2020), os sistemas de educação não sabem como lidar com essa crise especificamente e é preciso, reconhecer o não saber, entendendo, porém, que é essencial agir em defesa de uma educação que seja, sobretudo, pautada na luta contra as desigualdades sociais. Assim, interromper as atividades pedagógicas não deveria ser uma opção sob o risco de o estudante não retornar ao espaço escolar.

\section{Considerações finais}

O presente artigo teve como objetivo conhecer sobre juventudes, educação e o uso das tecnologias como ferramenta de aprendizagem em tempos de pandemia da covid-19 utilizou-se a análise bibliográfica, em que a pesquisa de revisão bibliográfica foi realizada por meio do levantamento, seleção e estudo de diversas pesquisas que versam sobre juventude; educação; uso das tecnologias como ferramenta de aprendizagem e pandemia da covid-19.

Por meio do presente estudo ficou evidenciado que as transformações sociais, políticas, econômicas, culturais e tecnológicas impõem, hoje, uma (re)significação dinâmica e constante das relações entre os indivíduos em todas as esferas: na família, no trabalho, no momento/local 
de lazer, na comunidade, nas redes sociais virtuais, e também, na escola, e que os jovens são os sujeitos submerso nessas transformações sociais. Evidenciou-se ainda, que diante das diversas alterações existentes no mundo e no mercado de trabalho, estão os jovens, em busca de Educação de qualidade para enfim conseguirem o tão sonhado primeiro emprego. Estes jovens hoje são indivíduos que mudam o mundo do trabalho, entretanto atualmente poucos conseguem emprego nas carreiras almejadas.

Constatou-se que os jovens da geração $y$ são motivados por desafios e interesse de ascensão rápida, buscando rotatividade nas suas atividades, essa nova geração possui importantes particularidades, pois nasceu na era da tecnologia, da internet e do acesso de informação, não passou por nenhuma importante ruptura no parâmetro social, habituado com a democracia, a liberdade política e prosperidade econômica.

Por outro lado, ficou claro que, no Brasil, existem poucos serviços voltados à juventude, e poucos deles apresentam propostas inovadoras e emancipatórias que possam levar a um salto em relação à sua qualidade de vida. Não existe, de fato, uma política pública eficaz para que o jovem alcance a sua inserção e inclusão social. No contexto de nossa sociedade, as políticas sociais voltadas para a juventude refletem as perspectivas do mundo adulto, que detém a responsabilidade pelo desenvolvimento e pela socialização dos seus jovens, e detém também o poder de decisão fato que acontece tanto no âmbito da família como do Estado.

Diante da realização de tal estudo, para estabelecer um padrão nas análises, a classificação de juventude abordada neste estudo está de acordo com a PEC da Juventude aprovada pelo Congresso Nacional, em setembro de 2010, e o Estatuto da Juventude sancionado em 2013 portanto considera-se jovem no Brasil todo cidadão que compreende a idade entre 15 e 29 anos de idade.

Evidenciou-se ainda, que no campo da educação a crise causada pela covid-19 resultou no encerramento das aulas em escolas e em universidades, afetando mais de $90 \%$ dos estudantes do mundo e que diante da pandemia que atravessamos neste momento um debate se faz necessário entre professores, pois quando as escolas reabrirem, a emergente recessão econômica, certamente, aumentará as desigualdades e poderá reverter o progresso obtido por alguns países na expansão do acesso educacional e na melhoria da aprendizagem. Por isso, é necessário que os países reconheçam o problema, como não o fizeram quando a covid-19 começou a espalhar-se pelo mundo, e criem políticas públicas voltadas especificamente para a Educação.

Ficou esclarecido que apesar da Educação a Distância (EAD) já ser uma realidade na educação brasileira, ele estava direcionado quase que na sua totalidade para o Ensino Superior, sendo outra parte para os cursos técnicos profissionalizantes. Na Educação Básica (Educação Infantil, Ensino Fundamental e Médio), a regra geral das escolas, quando utilizadas, tendia para o EAD apenas como forma de educação complementar, sendo autorizado o EAD para casos específicos do Ensino Médio, especialmente para cursos profissionalizantes.

A covid-19 nos levou a uma as situações emergenciais, afastando os alunos presenciais, da educação básica e do ensino superior, das salas de aula, devido a situação os gestores educacionais ficaram naturalmente atônitos e a reação demorou um pouco a ocorrer. Surgiram, então, as necessidades de adaptação e de superação, tanto por parte da gestão, dos professores quanto pelos estudantes, incluindo toda a sociedade, foram criados mecanismos como as tecnologias e programas como: Sistema Moodle; Google Classroom; Google Meet, dentre outros com intuito de auxiliar o trabalho dos professores e consequentemente contribuir no processo de aprendizagem dos jovens/estudantes.

Por outro lado, evidencia-se que o maior desafio da educação brasileira passou a ser a adequação ao novo cenário imposto pela pandemia, além da ausência de desenvolvimento de habilidades e competências digitais por parte dos professores, de maneira ainda mais urgente pois, a implantação do ensino remoto vem evidenciando ainda mais as disparidades socioeconômicas e culturais existentes no Brasil. 
Por fim, ressalta-se que de nada adianta para o jovem/estudante os programas e tecnologias existentes se a grande maioria deles não tem acesso às tecnologias, aplicativos e a internet para serem usadas como ferramenta de aprendizagem. Por outro lado, os sistemas de educação não sabem como lidar com essa crise especificamente e é preciso, reconhecer o não saber, entendendo, porém, que é essencial agir em defesa de uma educação que seja, sobretudo, pautada na luta contra as desigualdades sociais.

\section{Referências}

BRASIL. Lei no 11.129, de 30 de junho de 2005. Institui o Programa Nacional de Inclusão de Jovens - ProJovem; cria o Conselho Nacional da Juventude - CNJ e a Secretaria Nacional de Juventude; altera as Leis nos 10.683, de 28 de maio de 2003, e 10.429, de 24 de abril de 2002; e dá outras providências. Brasília, DF: Presidência da República, 1996.

BRASIL. Lei no 9.394, de 20 de dezembro de 1996 (Lei das Diretrizes e Bases da Educação). Estabelece as diretrizes e bases da educação nacional. Brasília, DF: Presidência da República, 1996.

COLOMBY, Renato Koch; SALVAGNI, Julice; CHERON, Cibele (org.). A Covid-19 em múltiplas perspectivas. 1. ed. Goiânia: Editora Espaço Acadêmico, 2020.

CONDÉ, Ágatha Alexandre Santos. Juventude e educação: os sentidos do ensino médio na periferia do Distrito Federal. 2016. 123 f. Dissertação (Mestrado em Ciências Sociais) - Universidade Federal de Uberlândia, Uberlândia, 2016.

DAYRELL, Juarez. O jovem como sujeito social. Revista Brasileira de Educação, Rio de Janeiro, n. 24, p. 40-52, dez. 2003.

DIAS, Érika; PINTO, Fátima Cunha Ferreira. A educação e a Covid-19. Ensaio: Avaliação em Políticas Públicas em Educação, Rio de Janeiro, v. 28, n. 108, p. 545-554, jul./set. 2020.

GABATZ, Celso. A reflexão crítica e científica em tempos de Covid-19: possíveis contribuições ao debate. In: COLOMBY, Renato Koch; SALVAGNI, Julice; CHERON, Cibele (org.). A Covid-19 em múltiplas perspectivas. 1. ed. Goiânia: Editora Espaço Acadêmico, 2020. p. 21-34.

KRENAK, Ailton. Ideias para adiar o fim do mundo. São Paulo: Companhia das Letras, 2019.

MACIEL, Natália Bertuol. Valores que influenciam a retenção dos profissionais da Geração Y nas organizações. 2010. $69 \mathrm{f}$. Trabalho de Conclusão de Curso (Graduação em Administração) - Escola de Administração, Universidade Federal do Rio Grande do Sul, Porto Alegre, 2010.

MBEMBE, Achille. Necropolítica: biopoder, soberania, estado de exceção, política da morte. São Paulo: N-1, 2018.

MELLO, Juliana Leitão e. Transições para a vida adulta: os jovens da região metropolitana do Rio de Janeiro. 2005. 149 f. Dissertação (Mestrado em Ciências e Estatísticas), Instituto Brasileiro de Geografia e Estatística, Rio de Janeiro, 2005.

MOREIRA, Eduardo. A economia do desejo e a COVID-19. In: TOSTES, Anjuli; MELO FILHO, Hugo (org.). Quarentena: reflexões sobre a pandemia e depois. Bauru: Canal 6, 2020. p. 61-64.

NÓVOA, António. Formação Continuada - Aula Magna António Nóvoa. Palestra proferida na abertura da Formação Continuada Territorial à Distância. Salvador: IAT, abr. 2020. Disponível em: https://www.youtube.com/watch?v=wx-deAxdegE. Acesso em: 20 jan. 2021.

OLIVEIRA, Sidnei. Geração y: era das conexões, tempo de relacionamentos. São Paulo: Clube de Autores, 2009.

PASINI, Carlos Giovani Delevati; CARVALHO, Élvio de; ALMEIDA, Lucy Helen Coutinho. A educação híbrida em tempos de pandemia: algumas considerações. Santa Maria: Observatório Socioeconômico/UFSM, 2020.

PEREIRA, Marcio Donizeti; BARROS, Edjane Angelo de. A educação e a escola em tempos de Corona Vírus. Scientia Vitae, São Paulo, v. 9, n. 28, p. 1-7, abr./jun. 2020.

RODRIGUES, Sindy Luciane Lago; RODRIGUES, Zita Ana Lago. A educação formal, a pandemia da Covid-19 e o princípio da responsabilidade social e ética na adoção das tecnologias - NTICs. In: COLOMBY, Renato Koch; SALVAGNI, Julice; CHERON, Cibele (org.). A Covid-19 em múltiplas perspectivas. 1. ed. Goiânia: Editora Espaço Acadêmico, 2020. p. 49-63. 
RODRIGUES, Thiago Machado. Juventude mercado de trabalho no Brasil: formação e empregabilidade. 2017. 86 f. Dissertação (Mestrado em Administração de Empresas) - Pontifícia Universidade Católica de São Paulo, São Paulo, 2017.

SANTOS, Boaventura de Sousa. A cruel pedagogia do vírus. Coimbra: Almedina, 2020.

UNESCO. A Comissão Futuros da Educação da Unesco apela ao planejamento antecipado contra o aumento das desigualdades após a COVID-19. Paris: UNESCO, 16 abr. 2020. Disponível em: https://pt.unesco.org/news/comissao-futuros-da-educacao-da-unesco-apela-ao-planejamento-antecipado-o-aumento-das. Acesso em: 28 jan. 2021.

VIEIRA, Márcia de Freitas, SILVA, Carlos Manuel Seco da. A Educação no contexto da pandemia de COVID-19: uma revisão sistemática de literatura. Revista Brasileira de Informática na Educação, Porto Alegre, v. 28, p. 1013-1031, 2020.

Data de submissão: 31/01/2021

Data de aceite: 16/02/2021 